\title{
Structuring the World down to cities and sustainable air sharing
}

\author{
H. H. Kleizen \\ Delft University of Technology, The Netherlands
}

\begin{abstract}
Cities live and need air to breathe. The annual air consumption of human activities in the Sustainable Technological World (STW) is prescribed (2006 thesis). This STW budget is shared by people. Densely populated areas have a larger air budget than less dense ones.

The structure of human societies in subsocieties is described with a logarithmic distribution. This novel 5 parameter topdown model allows the description of the World in countries, countries in provinces and provinces in cities enabling one to study scale effects (entities with the same sub entity structure). It is shown that the Dutch province Zuid-Holland with two large cities (Rotterdam and The Hague) has the same structure as the World with two large countries (China and India).

The cities and countries - embedded in their environment (Zuid-Holland, World) - are compared with respect to the categories of geography, people, government and transportation. It is concluded that indeed scaling occurs between Rotterdam and China and between The Hague and India. The differences in carbon dioxide emissions are reviewed with respect to air consumption allowed by the STW.

Keywords: air, carbon dioxide emissions, China and Rotterdam, cities, countries, government, India and The Hague, novel society model, Sustainable Technological World, World and Zuid-Holland.
\end{abstract}

\section{Introduction}

There is vast amount of literature about human societies through the ages. Brotchie et al. [1] state that cities are in competition and according to Rusk [2] with counties and there are well-known cases where cities have become identical 
with countries. While it is commonly accepted that cities are growing, acquire the status being the centre of metropolitan areas and end up with lack of control and stop blooming. The question addresses in this paper is what can cities learn from larger units - and vice versa- to ensure a sustainable life.

A top-down approach is preferred. The paper starts with a summary of a Sustainable Technological World as described by Kleizen [3]. It has, like the hydrosphere and the biosphere, sustainable relationships with the atmosphere, the tiny shell around the earth allowing mankind to breath.

The world is divided in land and water and 236 pieces of land (countries) can be extracted from the CIA World Factbook [4] are populated by human beings. These countries are subdivided in smaller units (say counties) and these smaller units in cities. A novel method is presented to describe the world and its (political) subdivisions, in terms of 5 variables. This enables to compare countries, counties and cities and study scale effects.

It has been found that the Dutch province Zuid-Holland has the same 4 structural parameters as the World. The Dutch cities Rotterdam and The Hague play the role of China and India in Zuid-Holland Scene. The major properties of these cities and countries are compared. The paper ends with a vision of the air the have breath in the STW calculating the time of air refreshment from allowed mass stream and stagnant amount of air available.

\section{Sustainable Technological World}

The relevant parts of the STW concept as presented in Kleizen [3] are summarized. Humans are part of the living matter on Earth together forming the biosphere. The biosphere is dispersed in the upper region of the Earth called the geosphere. The geosphere contains three subspheres: the atmosphere, hydrosphere and the lithosphere.

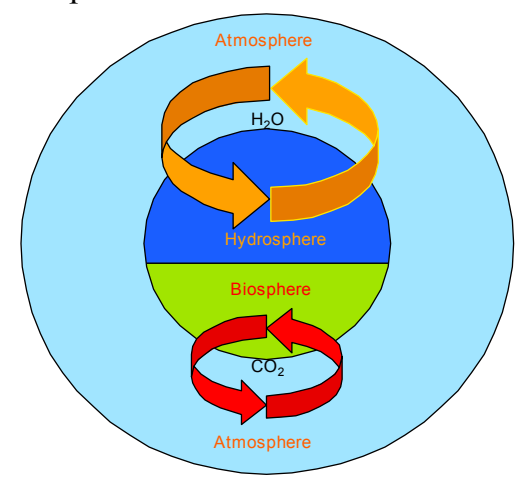

Figure 1: The 2 grant cycles on Earth.

The geosphere contains three subspheres: the atmosphere, hydrosphere and the lithosphere. Where the atmosphere meets a water surface mass exchange and life occurs: wet soil (the lithosphere) or seas (the hydrosphere). The two great cycles on Earth are depicted in Figure 1. 
The greatest cycle is the mass exchange between hydrosphere and atmosphere. The 1.7 billion Gton (Lide and Frederikse [5]) heavy hydrosphere evaporates annually about 540 thousand Gton (Houghton [6], Grübler [7]) water and gets it back as precipitation from the 5.1 million Gton ((Lide and Frederikse [5]) weighing atmosphere. Meanwhile the biosphere, with an estimated mass of 5.7 thousand Gton (Smil [8]), inhales 300 Gton/yr (Smil [8], Dunn [9]) carbon dioxide from the atmosphere reduces it and sends it back after oxidation. The two cycles are coupled to energy exchange. The H-cycle between atmosphere and hydrosphere involves the vaporisation and condensation of water and the $\mathrm{C}$ cycle between biosphere and atmosphere the carbon fixation in plants and carbon oxidation in plants and animals.

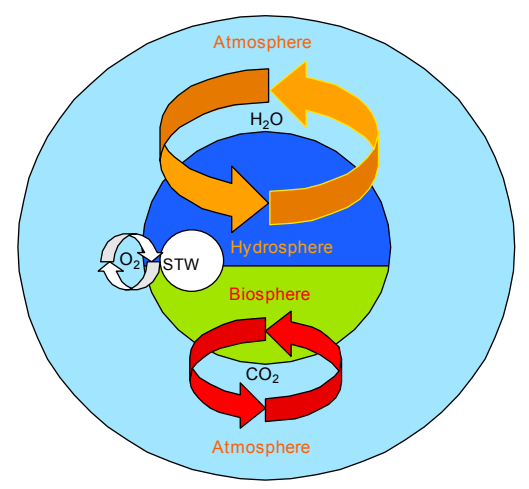

Figure 2: $\quad$ The STW the $3^{\text {rd }}$ cycle.

A third cycle involves the STW, the sustainable collection of technological artefacts on Earth. See Figure 2. The mass of the STW and its molar flux to and from the atmosphere is postulated making two assumptions about the position of the STW with respect to hydrosphere and biosphere. Oxygen is selected as the characteristic molecule shuttling between STW and atmosphere and water reduction is chosen to maximise the power associated with oxygen exchange. The major properties of the STW are collected in Table 1.

Table 1: $\quad$ STW properties.

\begin{tabular}{lll}
\hline Basic properties & & \\
\hline Mass STW & 110 & $\mathrm{Gton}$ \\
Power STW & 8800 & $\mathrm{GW}$ \\
Life-span artifacts, average & 25 & $\mathrm{yr}$ \\
\hline Benchmarks & & \\
\hline Annual production of artifacts & 4.4 & $\mathrm{Gton} / \mathrm{yr}$ \\
Specific energy consumption producing artifacts & 64 & $\mathrm{MJ} / \mathrm{kg}$ \\
Specific power consumption STW & 80 & $\mathrm{~W} / \mathrm{kg}$ \\
\hline Air and water flows & & \\
\hline Air & 375 & $\mathrm{Gton} / \mathrm{yr}$ \\
Water & 100 & $\mathrm{Gton} / \mathrm{yr}$ \\
\hline
\end{tabular}




\section{Structuring the World down to cities}

The population of a society can be classified using a logarithmic distribution like in filtration. The population is described by $2^{\mathrm{N}}$ with $\mathrm{N}$ an integer and therefore a class width of 2 . (In each class the number of people varies from $\mathrm{N} / \sqrt{2}$ up to $\mathrm{N} \sqrt{2}$.) In the CIA World Factbook [4] one counts 236 counties (nations, dependent areas and other entities) permanently populated by 6.446 billion people (July 2005 estimate). In Figure 3 the distribution over the World population over de 236 countries is sketched in terms of $\mathrm{N}$.

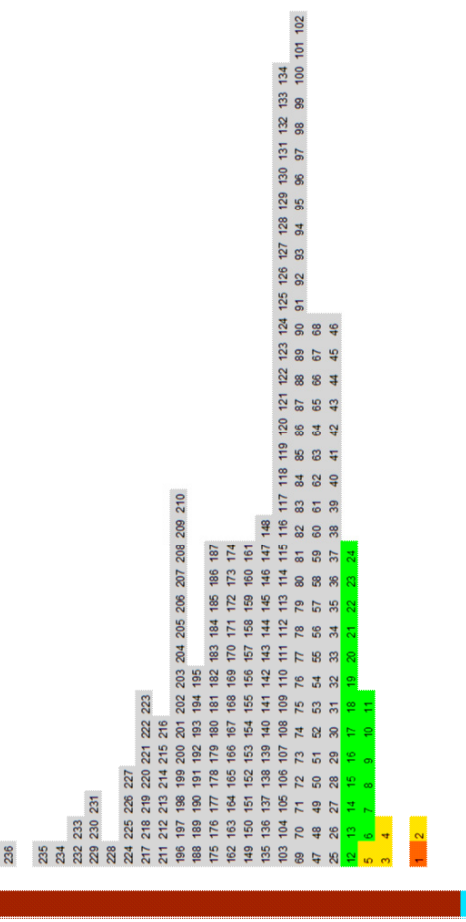

Figure 3: The World population distributed over 236 countries in terms of N.

The World population fells in class $\mathrm{N}=33$. The largest countries China and India are in class $\mathrm{N}=30$ and the smallest one - the Pitcairn Islands - with a population of 46 are in class $\mathrm{N}=6$.

To describe the World top down a second variable is introduced: the order $\mathrm{m}$ of the distribution. The order $\mathrm{m}$ is equal to difference between the $\mathrm{N}$-value of the society and the one of the largest subsociety. Thus the world has the order 3 (33$30=3$ ). Too complete the topdown description three indices hkl are introduced, which satisfy the tcondition,

$$
2^{N}=h \cdot 2^{N-m}+k \cdot 2^{N-m-1}+l \cdot 2^{N-m-2}
$$


with $1, \mathrm{k}=0,1,2,3$ and $\mathrm{h}=1,2,3, \ldots$ since there is at least 1 largest subsociety. The number of hkl solutions is equal to $4^{\mathrm{m}}$ as can be verified from Table 2 . To avoid confusion the k-indices are underlined.

Table 2: $\quad$ The hkl solutions for $\mathrm{m}=0,1$ and 2 .

\begin{tabular}{|c|c|c|c|c|c|c|}
\hline $\mathrm{m}=0$ & $\mathrm{~m}=1$ & \multirow[b]{2}{*}{ hkl } & \multicolumn{4}{|l|}{$\mathrm{m}=2$} \\
\hline hkl & hkl & & hkl & hkl & hkl & hkl \\
\hline 100 & 200 & \multirow{3}{*}{$\begin{array}{l}1 \underline{2} 0 \\
1 \underline{12} \\
104\end{array}$} & $4 \underline{00}$ & \multirow{3}{*}{$\begin{array}{l}3 \underline{2} 0 \\
3 \underline{12} \\
3 \underline{0} 4\end{array}$} & $2 \underline{4} 0$ & $1 \underline{6} 0$ \\
\hline & & & & & 232 & 152 \\
\hline & & & & & $2 \underline{2} 4$ & $1 \underline{4} 4$ \\
\hline & & & & & 216 & $1 \underline{3} 6$ \\
\hline & & & & & $2 \underline{0} 8$ & $1 \underline{2} 8$ \\
\hline & & & & & & $1 \underline{11} 10$ \\
\hline & & & & & & $1 \underline{0} 12$ \\
\hline
\end{tabular}

The world with $\mathrm{N}=33, \mathrm{~m}=3, \mathrm{~h}=2$ (China and India), $\underline{\mathrm{k}}=\underline{0}$ (no country with $\mathrm{N}=29$ ) gets then an 1-value of 24 as calculated from equation (1).

Many other societies were described in terms of the 5 parameters in search for a society with the same order and indices as the World. In the end it turned out that the Dutch province Zuid-Holland has the same order $\mathrm{m}=3$ and indices $\mathrm{h} \underline{\mathrm{kl}}=2 \underline{0} 24$ as the World.

\section{World and Zuid-Holland}

The World and its 2 largest countries are in Table 3 compared with the Dutch province Zuid-Holland and its 2 largest cities. The system of the table is copied from the sequence followed by the CIA World Factbook [4], highlighting only the themes Geography, People, Government and Transportation and disregarding the other 3 CIA Factbook themes: Economy, Military and Transnational Issues due to lack of comparable data. The CIA World Factbook deals with countries not with Dutch Provinces and their cities. All data regarding Zuid Holland, Rotterdam and The Hague are collected under references [10] up through [18]. Not all data given for the World, China and India can be found in [4]; these additional data cam be extracted from the references [19] through [23]. Some words have different meaning in different societies: (i) parliament = National People's Congress $($ China $)=$ Lok Sabha $($ India $)=$ Provinciale Staten (Zuid-Holland) = gemeenteraad (Rotterdam, The Hague), (ii) independence = recognized entity (Zuid-Holland) = city rights and (iii) the governmental power of administrative subdivisions varies, being zero in The Hague.

In the category Geography the cities relate to Zuid Holland as countries to the World. The exception is the carbon dioxide emission pro capita of Rotterdam and China. In the category People heading the same can be noted. The median age of The Hague and India are in line with Zuid-Holland and the World, but the median ages of Rotterdam and China show opposite figures. Under the heading Government it is clear that The Hague lacks an administrative subdivision. In all other societies there is one and interpreted in terms of the 5 parameters having in 
common the order $\mathrm{m}=3$, giving thereby each administrative subdivision little power. Rotterdam is the only society here the large subsocieties (deelgemeenten) can have a majority. The 5-parameter description can also be applied to the seats of the parliament (society) and seats of political parties represented in it (subsocieties). Since there is no World government this procedure cannot be carried out for the World.

Table 3: Comparing the World and its 2 largest countries China and India with the Dutch province Zuid-Holland and its 2 largest cities Rotterdam and The Hague.

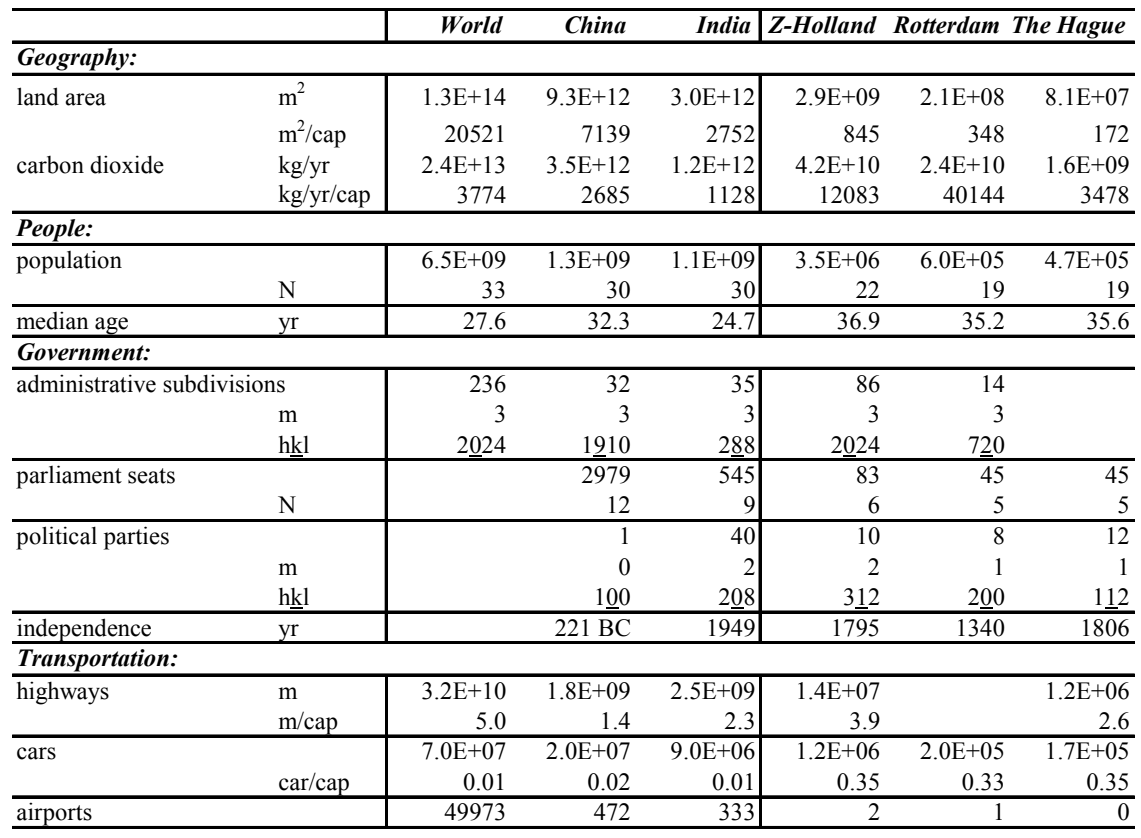

The number of seats and political parties vary greatly, but $\mathrm{m}$ is smaller facilitating parliamentary majorities. A majority is easier achieved in China and Rotterdam then in India and The Hague. China and Rotterdam are older then India and The Hague, contributing to the list of corresponding phenomena. In the category Transportation, the length of the highways in Rotterdam is unknown. The Hague and India relate similar to Zuid-Holland and the World. This is also true for the number of cars pro capita, whereas Rotterdam has relatively less cars then China. Finally the number of airports is line with expectations: The Hague less then Rotterdam and India less then China.

Summarizing it is remarked that the comparison makes sense and that differences between India and The Hague are smaller then those between China and Rotterdam. 


\section{Air residence time in the perspective of the STW}

In the STW the annual air flow is maximised (See Table 1) and this allocated to each human soul on Earth. On the other hand, the grammage, the amount of air per unit Earth surface, is limited too: $10^{4} \mathrm{~kg} / \mathrm{m}^{2}$ as calculated from Earth surface area and mass of the atmosphere (data: [5]). Knowing the land area populated by the society allows then the calculation of residence time $\tau$, from the equation,

$$
\tau=G \cdot \frac{a_{c}}{q_{c}}
$$

with $\mathrm{G}$ the grammage $\mathrm{kg} / \mathrm{m}^{2}$ and ac the number $\mathrm{m} 2$ /capita (See table 3) and qc the airflow in $\mathrm{kg} / \mathrm{m}^{2} / \mathrm{cap}$. The air flow depends only the number of people on Earth and for a World population of 6.446 billion people, the STW air flow is 5.8 $\mathrm{e} 4 \mathrm{~kg} / \mathrm{m}^{2} / \mathrm{cap}$, so the air residence time of the STW can be calculated

Another value of can be calculated from the carbon dioxide emissions. The conversion factor of 17 is derived from the human air breathing and carbon dioxide production [3]. In Table 4 the two residence times are compared.

Table 4: $\quad$ Comparison of STW and actual residence time.

\begin{tabular}{|c|c|c|c|c|c|c|c|c|}
\hline & & & World & China & India & Z-Holland & Rotterdam & The Hague \\
\hline \multicolumn{9}{|c|}{ Geography anf People: } \\
\hline$\overline{\text { res time }}$ & actual & $\mathrm{yr}$ & 3200 & 1600 & 1400 & 41 & $\overline{5}$ & 29 \\
\hline res time & STW & $\mathrm{yr}$ & 3600 & 1200 & 480 & 150 & 60 & 30 \\
\hline
\end{tabular}

In the perspective of the STW the city The Hague is sustainable, the World a bit unsustainable, China and India can increase their air production and Rotterdam is definitely invited to reduce its air production.

\section{Discussion}

The combination of the STW and the 5 parameter description of societies has the potential to become a powerful tool for developing pathways towards a sustainable future of planet Earth. It is applicable towards any society as demonstrated by the parliamentary seats, so also towards companies and other human organisations.

For one thing more data are needed and especially more transparent data on the societies on scale classes. Governments should agree upon the list of prime parameters and definitions to have a planet Earth where sustainability is transparent enabling all societies to see the different pathways Data should be reliable: the procedures to arrive at a certain estimate should be known too.

It is claimed that societies of different scale $(\mathrm{N})$ can be compared once the order $\mathrm{m}$ and the indices $\mathrm{hk} \mathrm{l}$ are identical. This statement could use additional proof. Exploring other cases with the same set of 4 parameters is in progress and will be reported elsewhere. 
The specific result is that Rotterdam and The Hague embedded in the Dutch province Zuid-Holland can be compared with the 2 largest countries in: China and India. And where the comparison fails other reasons should surface. This work is also in progress.

One of these reasons is of course historical development. For the future the STW can serve as a benchmark. The very idea of breathing chimney air alone should contribute to an increased awareness for the technological air production which by definition is contaminated, as fossil combustion processes are too difficult to ensure production of only carbon dioxide. An acceptable value for the residence time is of course open the discussion, but sustainable cities should aim at least for a time of 25 years.

\section{Conclusions}

The combination of STW and 5 parameter description of societies is a powerful tool in guiding societies towards sustainable development.

Globally China and India play a similar role as Rotterdam and The Hague in the province Zuid-Holland.

The STW helps in choosing between opposing trends.

\section{References}

[1] Brotchie, J., Batty, M., Blakely, E., Hall, P. \& Newton P., (eds), Cities in Competition, Productive and sustainable cities for the 21 sr century, Longman Australia: Melbourne, 1995.

[2] Rusk, D., Cities without Suburbs, Woodrow Wilson Center Press: Washington D.C., 2003.

[3] Kleizen H.H., Towards a Sustainable Technological World, Thesis Delft University of Technology, in press, 2006.

[4] CIA - The World Factbook, www.cia.gov/cia/publications/factbook/geos/in.html

[5] Lide, D.R. \& Frederikse, H.P.R., (eds), Handbook of Chemistry and Physics, CRC Press: Boca Raton, Ann Archor, London \& Tokyo, pp. 144 \& 14-5, 1993.

[6] Houghton J., Global Warming: The complete Briefing, Cambridge University Press: Cambridge, 1997.

[7] Grübler, A., Technology and Global Change, Cambridge University Press: Cambridge, 1998.

[8] Smil, V., Elementaire Kringlopen- Wisselwerking tussen biosfeer en beschaving, Natuur \& Techniek: Amsterdam, 1999. Dutch translation of: Smil., V., Cycles of Life, Civilization and the Biosphere, The Scientific American Library: New York, 1997.

[9] Dunn, S., Decarbonizing the Energy Economy, in: State of the World 2001, A Worldwatch Institute Report on Progress towards a Sustainable Society, W. W. Norton \& Co: New York, Chapter 5, pp. 83-102, 2001. 
[10] Land area and administrative subdivisions Zuid-Holland, Rotterdam \& The Hague, www.sdu.nl/staatscourant,scdata/adv frameset/html.

[11] Population Zuid-Holland, Rotterdam \& The Hague home.wxs.nl//pagklein/gemprov.html.

[12] 2002 Carbon dioxide emissions Zuid-Holland, Rotterdam \& The Hague, www.emissieregistratie.nl.

[13] Age distribution Zuid-Holland, Rotterdam \& The Hague, CBS periode 2004, cbs.nl.

[14] Parliament (Provinciale Staten) seats, political parties \& highways ZuidHolland, pzh.nl.

[15] Parliament (Gemeenteraad) seats \& political parties Rotterdam, www.rotterdam.nl.

[16] Parliament (Gemeenteraad) seats, political parties \& highways The Hague, www.denhaag.nl.

[17] Cars in Zuid-Holland: www.scp.nl, Cars in Rotterdam \& The Hague, www.grotevier.nl.

[18] Airports in Zuid-Holland, Rotterdam \& The Hague, www.aircraft-charterworld.com/airports/europe/netherlands.htm.

[19] Land area World, sum of populated countries calculated from [4] data.

[20] 2002 Carbon dioxide emissions, World, China \& India, cdiac.ornl.gov/trens/emis/top2002.tot.

[21] Parliament (National people's Congress) and seats China, www.lexas.net

[22] Parliament (Lok sabha) and seats India, www.indianelections.com/resultsupdate.

[23] Cars of the World, www.cambridgeesol.org, cars of China, www.chinadaily.com.cn, cars of India, www.atimes.com. 